\title{
The present-day number of tectonic plates
}

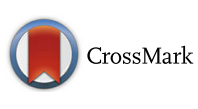

\author{
Christopher G. A. Harrison
}

\begin{abstract}
The number of tectonic plates on Earth described in the literature has expanded greatly since the start of the plate tectonic era, when only about a dozen plates were considered in global models of present-day plate motions. With new techniques of more accurate earthquake epicenter locations, modern ways of measuring ocean bathymetry using swath mapping, and the use of space based geodetic techniques, there has been a huge growth in the number of plates thought to exist. The study by Bird (2003) proposed 52 plates, many of which were delineated on the basis of earthquake locations. Because of the pattern of areas of these plates, he suggested that there should be more small plates than he could identify. In this paper, I gather together publications that have proposed a total of 107 new plates, giving 159 plates in all. The largest plate (Pacific) is about $20 \%$ of the Earth's area or 104 Mm², $^{2}$ and the smallest of which (Plate number 5 from Hammond et al. 2011) is only $273 \mathrm{~km}^{2}$ in area. Sorting the plates by size allows us to investigate how size varies as a function of order. There are several changes of slope in the plots of plate number organized by size against plate size order which are discussed. The sizes of the largest seven plates is constrained by the area of the Earth. A middle set of 73 plates down to an area of 97,563 $\mathrm{km}^{2}$ (the Danakil plate at number 80 , is the plate of median size) follows a fairly regular pattern of plate size as a function of plate number. For smaller plates, there is a break in the slope of the plate size/plate number plot and the next 32 plates follow a pattern of plate size proposed by the models of Koehn et al. (2008) down to an area of 11,638 $\mathrm{km}^{2}$ (West Mojave plate \# 112). Smaller plates do not follow any regular pattern of area as a function of plate number, probably because we have not sampled enough of these very small plates to reveal any clear pattern.
\end{abstract}

Keywords: Plate tectonics, Small plates, Plate size, Plate fracturing

\section{Introduction}

Since the start of plate tectonics, the number of recognized plates has grown considerably. This introduction examines how this number has grown with time. The first attempt at a global description of plates was done by Morgan (1968). Additional file 1: Table S1 shows the plates that can be identified in his first figure, as well as plates used in some other models. Although there are 14 plates on Morgan's list, he did not make estimates of plate motion for most of them. Le Pichon (1968) published a model (with a correction in Le Pichon 1970) a few months after Morgan's paper and calculated the relative motions between the largest six plates. Morgan (1971) published a plate model with 15 plates, all of whose absolute motion rotation vectors were given, allowing relative motions between plate pairs to be

Correspondence: charrison@rsmas.miami.edu

Department of Marine Geosciences, Rosenstiel School of Marine and Atmospheric Science, University of Miami, Miami, FL, USA calculated. Hot spot traces were heavily used to determine absolute plate velocities.

Chase (1972) published the first self-consistent model of relative plate motions, in which the relative rotation vectors are solved together rather than individually for specific plate pairs. He used eight plates. The data consisted of 176 directions of relative motion and 59 rates of relative motion, allowing him to derive the relative rotation vectors. Minster et al. (1974) produced a second self-consistent model, RM1, using 11 plates. They used almost the same number of data as Chase (1972), consisting of 106 earthquake slip vectors, 62 fracture zone trends, and 68 rates of relative motion. Model AM1 is a variant of RM1 which describes plate motions in a "hot spot" reference frame. Chase (1978) produced a model with 12 plates, called P071 (P073 is a variant of this model which gives plate rotation vectors in the hot spot reference frame). He used 101 earthquake slip vectors, 69 transform fault trends, and 90 rates of relative motion. Minster and Jordan in the same year (1978) produced model RM2 (with its hot spot reference frame
算 Springer

(c) 2016 Harrison. Open Access This article is distributed under the terms of the Creative Commons Attribution 4.0 International License (http://creativecommons.org/licenses/by/4.0/), which permits unrestricted use, distribution, and reproduction in any medium, provided you give appropriate credit to the original author(s) and the source, provide a link to the Creative Commons license, and indicate if changes were made. 
counterpart AM1-2) using 142 earthquake slip vectors, 78 transform fault azimuths and 110 relative motion rates. They used 11 plates in their reconstruction.

A major increase in data was available to DeMets et al. (1990, 1994), who produced model NUVEL1 and NUVEL1A which was a revision to NUVEL1 caused by a slight change in the estimated age of the magnetic anomaly used to measure spreading rates. NUVEL1A has 14 plates, 12 of which were solved together, and 2 other plates used with rotation vectors coming from other investigations. The data used to solve for the 12 plates consisted of 724 earthquake slip vectors, 121 transform fault azimuths, and 277 relative motion rates. Although there were far more data available for this model, the only additional plate that they solved for, compared with the solution of Chase (1978), was produced by the splitting of the old Indian plate to create an Australian plate.

All of the models introduced so far have been based on geological information, such as average spreading rates over a few million years, earthquake fault plane solutions, and transform fault azimuths. New types of information can also be used to constrain plate motions, especially space-based methods such as very long baseline interferometry (VLBI), satellite laser ranging (Harrison and Douglas 1990; Robaudo and Harrison 1993), Doppler Orbitography and Radiopositioning Integrated by Satellite (DORIS), and most importantly today the Global Positioning System (GPS). These give relative motions over a few years to a decade or more. Larson and Freymueller (1997) analyzed GPS data for 38 sites and were able to calculate rotation vectors for eight plates. A more extensive analysis of GPS data (plus a few SLR and DORIS sites) to produce a self-consistent set of relative rotation vectors for many plates was done by Sella et al. (2002), who derived model REVEL. This model used 166 sites (producing 332 results) situated far enough away from plate boundaries that they record the movement of the plate interiors to derive the motions of nineteen plates. The number of data gathered for each site varied considerably. The use of space-based geodetic measurements produced a model with considerably more plates than had been obtained using geological information, as can be seen in Additional file 1: Table S1. But some well-established plates, such as the Cocos and Juan de Fuca plates, were not present due to lack of GPS observations on these mainly oceanic plates.

A model by Bird (2003) added many more plates, bringing the total to 52 . Most of these were small plates, some located in deformed areas of Earth's surface. Bird pointed out that his list of plates was probably incomplete for plates smaller than Shetland $\left(72,240 \mathrm{~km}^{2}\right)$, which is the fourth smallest in his list. With the addition of plates described below bringing the total to 159 , the
Shetland plate is now the 81st largest; so 32 plates have been added that are larger than this plate, and 75 have been added that are smaller.

At about the same time as Bird's (2003) paper was published, Kreemer et al. (2003) produced another global model (GSRM-1), using horizontal velocities and horizontal strain rates for "almost all deforming plate boundary zones". Three thousand geodetic velocities were used, mostly from published data. They used geological strain rates for central Asia and shallow earthquake information for other plate boundary areas. Their model included 19 plates for which rotation vectors are given and 6 other plates that had no geodetic velocity data.

Kogan and Steblov (2008) produced a model using GPS data from ten major lithospheric plates. They were concerned about allowing for the movement of the Earth's center, which, if not taken care of, can make GPS data a little degraded. Nine other plates were not analyzed for plate rotation, and some of these plates are quite large.

A new model was proposed by DeMets et al. (2010) as a replacement for NUVEL-1A, called MORVEL. They used far fewer earthquake slip vectors (the largest source of data for NUVEL-1A) because of small systematic errors in determining relative plate motion directions from earthquake slip vectors and far more spreading rate data (resulting in the name mid-ocean ridge velocity). They also used GPS data to define the movements of six plates. The number of data was 1696 spreading rates, $288 \mathrm{~N}$ and E velocities from 144 GPS stations, 163 transform fault azimuths, and 56 earthquake slip vectors, totaling 2203 in all. The number of plates was 29 but 4 of their suggested plates had no relative velocity information. Another space-based model called GEODVEL was produced by Argus et al. (2010). It consisted of an analysis of the movement of 11 plates using 206 sites where VLBI, SLR, GPS, or DORIS data were available.

Because of the indication that there may be additional small plates not yet counted, I decided to search for such plates and measure their area, so as to obtain and make a more complete catalogue of plate areas. The main point is to attempt to fill in the Bird catalogue with other plates, to see if the character of the plate size variation is significantly altered by these additions.

Thatcher (1995) has discussed whether continental deformation is more accurately described by a rigid plate model or whether a continuum model works better. Thatcher has been involved in several studies of small to very small plates (Thatcher 2007; Hammond and Thatcher 2007). The conclusion of the authors was that plates in which no internal deformation has been seen exist down to very small plate sizes. Thatcher (2009) has suggested that if the brittle-elastic crust is stronger than 
the ductile lithosphere then a block model is preferable, while if the opposite is true, then continuum models should be used. Thatcher also says in this paper that the upper crust is a load-bearing element in regions that are deforming, and so he prefers the block model, although he points out that there is disagreement about this.

My hypothesis is that if there is rigid behavior (i.e., no internal deformation, meaning that angles and distances are preserved away from plate edges), then this results in a plate. There will of course be elastic deformation at the edge of any plate due to the fact that the faults that form the plate boundaries are locked. Earthquakes will relieve this elastic deformation, which will then build up again in the next earthquake cycle. This is the definition of what plates are in most other publications.

It is possible that very small plates may reorganize themselves (an example being the Southern California Shear Zone) aperiodically. Small plates may be generated by forces different from those that form large plates. But if there is no internal deformation, then they should be called plates. Any attempt to divide the larger plates, which are assumed to last for a long time, from smaller plates, which may last for shorter times, seems to me to be arbitrary in that there is no easy way to define at what size this division should be made, apart from that discussed below.

\section{New plates}

\section{Individual plates}

The first set of new plates to be compiled in this paper consisted for the most part in studies of small areas where there was some evidence that individual plates should be split up as there appeared to be systematic errors between model and data. This produced 23 more plates, listed in Additional file 1: Table S2. As an example, there is the proposed Jalisco plate in southern Mexico (Johnson and Harrison 1990). Neotectonic results were analyzed, and it was found that this plate could be distinguished because of quaternary faults observed in Landsat images. We identified one block, called the Jalisco plate, which had a clear separation from the Rivera plate and also from the North American plate. We made an estimate of the motion of the Jalisco plate (now the 87th largest plate) with respect to North America by assuming uniform motion across the plate. This assumes that the pole of rotation is far enough away from the plate that no significant changes in relative motion vector occur within the confines of the plate. The result was a motion of $7 \mathrm{~mm} / \mathrm{a}$ in a direction of $\mathrm{N}$ $40^{\circ} \mathrm{E}$. In order to use a rotation pole to achieve this motion, the simplest is to put the pole $90^{\circ}$ from the plate on a great circle perpendicular to the direction of motion. This results in a pole at $-37.2^{\circ}$ $\mathrm{N},-31.0^{\circ} \mathrm{E}$ with a counterclockwise rotation rate of $0.063^{\circ} / \mathrm{Ma}$ with respect to North America. The area of the Jalisco plate is $46,291 \mathrm{~km}^{2}$ or $0.00908 \%$ of the Earth (in the calculation of area I have assumed an Earth area of $510 \mathrm{Mm}^{2}$ ). For two other blocks (the Guerrero and Michoacan blocks), their extents could not be determined and so they were not included in this analysis.

All of the other 23 plates have also come from the literature (see Additional file 1: Table S2). Areas were measured either by using a planimeter or by digitizing the plate boundaries and using the spherical excess property that the area is equal to the spherical excess $\left(\Delta_{n}\right)$ of an $n$-sided polygon in radians times the radius of the sphere squared (Bevis and Cambareri 1987)

$\Delta_{n}=\sum_{i=1}^{n} \theta_{i}-\pi(n-2)$

$A_{n}=\Delta_{n} \cdot R^{2}$

where $A_{n}$ is the area of the polygon and $R$ is the radius of the sphere.

The rotation vector for the Puerto Rico plate was obtained from a motion of $2.6 \mathrm{~mm} /$ year along $\mathrm{N}$ $82.5^{\circ} \mathrm{W}$ with respect to the Caribbean plate. One of the plates (Azores) has no relative rotation parameters. By far, the smallest plate in this list is the North Galapagos microplate. Its area is $1559 \mathrm{~km}^{2}$, which would be produced by a circle of $22.3 \mathrm{~km}$ radius. Klein et al. (2005) suggest that both the Galapagos plate and the North Galapagos microplate are driven by edge tectonics rather than by mantle drag (itself a controversial topic, e.g., Forsyth and Uyeda 1975). Edge tectonics will happen more easily when the plate is small because, in general, the boundary of the plate will be relatively larger compared with its surface area as the plate size shrinks. Looking at Additional file 1: Table S2, it can be seen that the eight smallest plates have been formed in divergent environments. All of these 23 plates are shown in Additional file 1: Table S1, which totals $52+23=75$ plates. The plates discussed below have not been added to Additional file 1: Table S1 because (a) it would make the table more unwieldy than it already is and (b) most of the plates suggested below have not been used in the other plate models whose data are shown in Additional file 1: Table S1. More than half 
of these plates were suggested subsequent to the publication of Bell's (2003) paper. Methods of determination of new plates consist of more detailed modeling of plate velocities and directions and determining where there are anomalies between the model and the observations requiring the addition of new plates. Also, new methods of measurement, especially the advent of GPS measurements, have been instrumental in finding more small plates.

2. Plates close to the Southern California Shear Zone Bird and Rosenstock (1984) have proposed a series of small plates in the region of the San Andreas Fault in southern California (the Southern California Shear Zone). They included 22 plates of which 17 had their complete boundaries identified, while the other 5 had parts of their boundaries out of the relevant figure. One of these five has appeared as the Sierra Nevada plate in Additional file 1: Table S2. Additional file 1: Table S3 gives a list of the 17 plates, with their areas. Several of the plates are quite elongated. Their velocities relative to the North America and Pacific plates are given in subsidiary documentation to Bird and Rosenstock (1984). These plates were defined using geological data consisting locations of young faults and 81 slip rates mostly of times since the opening of the Gulf of California. The 17 plates in Additional file 1: Table S3 were not included in Bird's (2003) analysis because a global analysis of such small plates was not yet practical at that time.

Meade and Hager (2005) studied the same area using GPS measurements. After having winnowed the data, they ended up by using 439 stations in their analysis, out of 840 stations. Based on the area in Fig. 4, this results in about 1 station per $1000 \mathrm{~km}^{2}$. If the stations were uniformly distributed, this would then allow most of the blocks in Additional file 1: Table S9 to have one or more stations. But of course, the stations are not uniformly distributed. Some areas have few stations, such as the San Andreas area and the southern part of the Pacific plate. The procedure used by Meade and Hager (2005) was to iterate starting with a fault map produced mainly by Jennings (1994) with input from other workers including Bird and Rosenstock (1984). Block model boundaries were modified to minimize residual velocity anomalies. Although the plates so defined do not necessarily agree with those in Bird and Rosenstock (1984), the average size and number of the plates is closely matched, although the plates using the GPS measurements tend to have a smaller areal spread than the earlier effort. The ratio between the smallest and largest plates in Meade and Hager is only about 11 whereas this ratio is about 34 for the plates in Bird and Rosenstock. The total area is almost the same and the number of plates differs by one. The use of either areas from Bird and Rosenstock (1984) or Meade and Hager (2005) does not have much effect on the size distribution, which is the main thrust of this paper. It is in fact remarkable because the Bird and Rosenstock (1984) model used results that in general stretched over a much longer time period than did the later paper. A third study of this area was carried out by McCaffrey (2005). His area was larger than those used by Bird and Rosenstock (1984) and Meade and Hager (2005) as it went further to the NW, enclosing the whole Sierra Nevada plate. GPS data were extensively used. McCaffrey believes that the data show the existence of "a finite number of rotating, elastic spherical blocks" such that "to a large degree the region can be represented with a plate tectonic style of deformation and relatively minor regions of small scale deformation". He allows for elastic deformation of the plate edges due to forces from surrounding plates and solves for this elastic deformation. The data used consist of 1710 horizontal GPS velocities from 1333 unique monuments, as well as 111 fault slip rates, 1 Gulf of California (GC) spreading rate, 5 GC transform fault azimuths, and 127 earthquake slip vectors. This represents almost 4000 data points. The plates used by McCaffrey (2005) are also listed in Additional file 1: Table S3 allowing a comparison with Bird and Rosenstock's results. The number of results used to define the 15 plates investigated by McCaffrey (2005) is 1830, giving an average of about 122 results per plate. Only four of these plates are used in the new master plate list because most of the area is covered by Bird and Rosenstock (1984). Comparison of the two studies shows that the Eastern California Coast Ranges and the Western California Coast Ranges from McCaffrey (2005) can be used as they are not covered by Bird and Rosenstock (1984). The complete Salinian plate and the complete Great Valley thrust belt (minus the Carrizo Plate) can also be added. Thus, this area of Western North America adds 21 more plates to the master list, 17 from column 1 Additional file 1: Table S3, and 4 from column 3 of Additional file 1: Table S3. The Salinian and West California Coast Range areas are deleted from the Pacific plate, and the Great Valley Thrust Belt and the East California Coast Range areas are deleted 
from the North American plate. The four additional plates had an average of 58 data to define their movement and an average area of $15,719 \mathrm{~km}^{2}$. Hammond et al. (2011) studied crustal deformation using GPS in the northern Walker Lane and Basin and Range region. The area that they studied overlapped the area McCaffrey (2005) examined, including a bit of the Sierra Nevada plate. Most of the area was within the Western Basin and Range plate of McCaffrey (2005) and a little overlapped his Eastern Basin and Range plate. Hammond et al. (2011) arrived at 31 plates whose boundaries were completely known (see Additional file 1: Table S4) out of a total of 60 plates. The smallest plate from Hammond et al. (2011) was 1.8 times smaller in area than the Plieto plate, the smallest plate in Bird and Rosenstock's list. This list of plates is biased towards the smaller plates in the study. Larger plates tend to stretch beyond the boundaries of the study area and are therefore not counted because of a lack of complete information about size. The average size of these 31 plates was $911 \mathrm{~km}^{2}$. The average size of the excluded plates was definitely larger than this. Although the number of GPS sites used to define the plate motions is much less than the number of GPS sites used by McCaffrey (2005), the authors insist that these small plates act in the same way as larger plates, having small internal deformation apart from elastic deformation at the plate edges caused by stuck bounding faults. The sites were occupied by 57 Trimble receivers in campaign mode, and great care was taken to allow the receivers to occupy exactly the same positions each time a site was occupied. This meant that the results from this work were in general better than a typical campaign mode operation would achieve. They also used observations from the Plate Boundary Observatory GPS stations which consist of a network of 1100 permanent, continuously operating GPS stations, many of which provide data at high rate and in real time, and some of which are within the area studied.

Hammond and Thatcher (2007) studied small plates which covered much of the area described by Hammond et al. (2011). One plate which was not completely covered by the area in Hammond et al. (2011) was the Mohawk plate. This plate had complete boundaries in Hammond and Thatcher (2007). Its motion was defined using 14 GPS sites. Its area is $14,515 \mathrm{~km}^{2}$, and this was removed from the North American plate. Thus, the whole area of the Southern California Shear Zone and other areas to its east (Basin and Range) contributed 52 new plates to the master list of plates.
3. Other areas

A study of the North Anatolian fault system (Meade et al. 2002) revealed an additional bloc whose western boundary was not shown so that its area cannot be determined from the data in the paper. Reilinger et al. (2006) used GPS data to study the area between Africa, Arabia, and Eurasia. Results are shown in Additional file 1: Table S5. This area was originally studied by McKenzie (1970, 1972) and McKenzie et al. (1970). The availability of dense GPS data, and the results of many focal plane measurements on earthquakes has allowed much progress to be made in understanding this area. Plate boundaries were determined by mapped faults, historic earthquakes, and seismicity. Elastic deformation at plate boundaries is allowed for in the modeling. Estimates of intra plate deformation are below 1-2 $\mathrm{mm} /$ year, indicating that these plates behaved rigidly and so could be counted as true tectonic plates. As outlined in Additional file 1: Table S5, 11 plates were added to the list. The data used for this study consisted of 337 GPS survey mode data and 103 continuous mode stations. The average time span of the measurements was about 5.3 years. Elastic deformation for locations close to bounding faults was allowed. Cavalié and Jónsson (2014) also studied part of this area using InSAR data and came to the conclusion that "our results support a tectonic model where plates, in the eastern Anatolian region, behave mostly as rigid blocks...".

Thatcher (2007) studied deformation in Tibet (Additional file 1: Table S6). He used the locations of major faults to define the edges of his (rigid) blocks and GPS velocities to obtain the relative motions of the blocks. Thatcher says that "where data are well distributed the velocity field can be explained well by rigid block motion and fault slip across block boundaries". The area studied does not overlap the area to the NW studied by Meade and Hager (2001). For the 11 identified plates, a total of 349 GPS velocity data was used. In contrast, both for this study and the next study of Tien Shan, Flesch et al. (2001) prefer a continuum model of these areas. Shen et al. (2005) also came to the conclusion that the continuum model worked better at the eastern end of the area studied by Thatcher; Thatcher's last words in his abstract were "Previous work has suggested that both GPS data and low fault slip rates are incompatible with rigid block motions of Tibet. The results reported here overcome these objections." Meade and Hager (2001) studied a portion of the Tien Shan area using GPS and fault locations. They 
arrived at a model with eight blocks, of which only five had their boundaries complete or almost complete. The areas of these five blocks are given in Additional file 1: Table S7. The plates are in general larger than the plates in the Southern California Shear Zone. The blocks were originally determined using the locations of important faults running through the area. Details of the GPS observations are not extensive, but the number of sites used was 147. These were occupied in campaign mode, probably about once a year (Abdrakhmatov et al., 1996). The concept of plates of low internal deformation is also agreed by Meade and Hager (2001) for this area. This analysis showed that velocity component errors were less than $2 \mathrm{~mm}$ /year. Figures show that each of the plates was observed using at least five GPS sites, and some plates were observed at far more sites than this. Comparing the GPS velocities of all the sites within the study area with what was predicted by uniform motions of the plates revealed that the mean residual velocity was close to zero and that almost all (more than $90 \%$ ) residual velocities were less than $2 \mathrm{~mm} /$ year. The velocity rates of the seven plates (some incomplete in area) relative to the Kazak Platform ranged between 2.25 and $13.65 \mathrm{~mm} /$ year.

Wallace et al. (2004b) studied the North Island of New Zealand and used GPS data, earthquake slip vectors, and geological fault slip rates to determine the movement of five separate blocks or plates west of the Hikurangi Trough, the boundary between the Pacific and Australian plates. The plate names and velocities are given in Additional file 1: Table S8. The variation of sizes of these plates is strangely similar to those in Additional file 1: Table S7. The authors describe these plates as "several, distinct, tectonic blocks". Wallace et al. (2004a) studied the area of Papua New Guinea and its surroundings. They found evidence of another plate, the New Guinea Highlands plate, but could not draw a complete boundary around the plate and so this plate is not included in the list of 159 plates. However, these authors did indicate that this and the other plates in the area (N. Bismarck, S. Bismarck, and Woodlark plates) are all acting as elastic tectonic plates with no permanent internal deformation.

Other plates have been proposed. There has been some suggestion that the Molucca Sea Plate could be divided into the Sangihe Plate and the Halmahera Plate (Hall and Spakman 2003). Since the boundaries of these proposed plates have not been drawn, I have left the Molucca Sea Plate, as described by Bird (2003), in place. Kusky et al. (2010) have proposed an extension of plate boundaries from the East African Rift to the eastern side of Madagascar, but in view of the fact that the full boundary of any additional plate is not given, nor is there a relative motion pole, this result has not been added to my list. Wallace et al. (2004a) have suggested the New Guinea Highlands Plate lying to the SW of the North Bismarck the South Bismarck, and the Woodlark plates, but without giving a complete picture of its extent.

Table 1 shows a list of the studies used to compile the catalogue of plates.

\section{Plate differentiation}

Bird's list of 52 plates was developed using normal observations to determine plate boundaries, and relative motions described instantaneous rotation parameters. The plate boundaries were selected using seafloor ages and spreading rates, topography/bathymetry, volcano locations, moment tensors of shallow earthquakes, locations of shallow earthquakes, known faults, and previous boundary locations from the literature. Not many space geodetic observations were used to obtain plate velocities. Most of the plates had been previously suggested but Bird occasionally modified their shapes or motions. Twelve "new" plates were proposed by Bird. The 23 plates in Additional file 1: Table S2 were developed using similar techniques to those used by Bird, small changes in direction of motion, discrepancies in spreading rates, greater knowledge of recent geology (volcanoes, earthquake locations), etc. Fifteen had not appeared in global analyses, and 8 had been recognized earlier in one or more of the global analyses listed in Additional file 1: Table S1. Only 22 of these plate areas were used because the Tarim Basin appears in Additional file 1: Table S6 with a slightly larger area, which has been used in the analysis.

Many of the other studies used locations of faults determined by geological methods, as well as earthquake locations and mechanisms, volcanic activity, and also space-based methods such as GPS observations which have become important over the past decade, especially for the relative motions of small plates, and the locations of their plate boundaries. Modeling will often accompany GPS data and will frequently allow for elastic strain at plate edges. The authors of all of the other analyses (Additional file 1: Tables S3-S8) state that a plate model, meaning no internal deformation and distances and angles are preserved, is the appropriate model for determining results that they obtained. Elastic deformation is naturally occurring at plate edges, and some authors have shown that this gives a reasonable explanation of 
Table 1 List of plates and analysis methods

\begin{tabular}{|c|c|c|c|c|c|c|}
\hline $\mathrm{L}$ & $\mathrm{T}$ & $\mathrm{N}$ & M & A & $\mathrm{R}$ & AM \\
\hline Worldwide & S1 & 52 & 4 & $9,807,692$ & Bird (2003) & $\begin{array}{l}\text { Classical analysis using SFS, fault and } \\
\text { earthquake locations, fault displacements, etc. }\end{array}$ \\
\hline Worldwide & $\mathrm{S} 1, \mathrm{~S} 2$ & 22 & 6 & 659,803 & See Additional file 1: Table S1 & $\begin{array}{l}\text { Ditto. Tarim Basin is not counted here but is } \\
\text { counted in Additional file 1: Table S6. }\end{array}$ \\
\hline scsz & S3 & 17 & 17 & 6702 & Bird and Rosenstock (1984) & $\begin{array}{l}81 \text { fault motions from geological estimates. } \\
\text { Relative block motion from vertical fault strikes. } \\
\text { Most ages are Pliocene-Quaternary. }\end{array}$ \\
\hline SCSZ & S3 & 4 & 4 & 16,120 & McCaffrey (2005) & $\begin{array}{l}23 \text { plates. Most of the area is covered by Bird } \\
\text { and Rosenstock (1984). } 3046 \text { GPS velocities, } 110 \\
\text { slip vectors, } 132 \text { slip azimuths. Plate boundaries } \\
\text { fixed by known faults. GPS vel. misfits are } 1 \mathrm{~mm} / \text { year. }\end{array}$ \\
\hline Basin and range & S4 & 31 & 31 & 862 & Hammond et al. (2011) & $\begin{array}{l}60 \text { plates. } 307 \text { sites occupied by } 57 \text { GPS receivers. In } \\
\text { addition, there were six continuous GPS sitesof the } \\
\text { PBO. Elastic strain close to perimeter is modeled. } \\
\text { Boundaries are obtained from mapped faults. }\end{array}$ \\
\hline Basin and Range & Mohawk & 1 & 1 & 25,748 & Hammond and Thatcher (2007) & $\begin{array}{l}\text { Mohawk has } 14 \text { GPS stations measured over a 4-year } \\
\text { period. Campaign sites have a } 1 \sigma \text { velocity uncertainty } \\
\text { of } 0.8 \mathrm{~mm} / \text { year, and for continuous sites, it is } 0.4 \mathrm{~mm} / \text { year. }\end{array}$ \\
\hline Mediterranean & S5 & 11 & 6 & 565,570 & Reilinger et al. (2006) & $\begin{array}{l}\text { "Substantial areas of continental lithosphere ... show } \\
\text { coherent motion with internal deformations below } \\
1-2 \mathrm{~mm} / \text { year." }\end{array}$ \\
\hline Tibet & S6 & 11 & 0 & 269,331 & Thatcher (2007) & $\begin{array}{l}5 \text { plates with } 233 \text { GPS sites allowed rotation pole calculation. } \\
\text { Another set of } 6 \text { plates with } 111 \text { GPS sites had translations } \\
\text { calculated, equivalent to rotation about a pole } 90^{\circ} \text { away. }\end{array}$ \\
\hline Tien Shan & S7 & 5 & 5 & 25,748 & Meade and Hager (2001) & $\begin{array}{l}\text { Block model developed from known fault segments with } \\
8 \text { blocks. Elastic deformation allowed close to plate edges. } \\
147 \text { GPS sites. Mean residual velocity } \sim 1.3 \mathrm{~mm} / \text { year. }\end{array}$ \\
\hline New Zealand & \$8 & 5 & 5 & 27,587 & Wallace et al. (2004b) & $\begin{array}{l}\text { GPS, earthquake, and geological slip rates used to demonstrate } \\
\text { that the tectonic block model works well for the boundary } \\
\text { zone. }\end{array}$ \\
\hline SCSZ & S9 & $17^{*}$ & & & Meade and Hager (2005) & $\begin{array}{l}439 \text { GPS stations. Mean uncertainty } 1.45 \mathrm{~mm} / \text { year. } 24 \text { blocks } \\
\text { modified from Jennings (1994) fault map. Elastic deformation } \\
\text { allowed near faults. }\end{array}$ \\
\hline
\end{tabular}

Total number of plates $=159.17^{*}$ not used. In addition, there are at least 39 plates whose boundaries are not complete

$L$ location, $T$ table number, $N$ number of plates, $M$ number of plates smaller than nick point, $A$ average area, km², $A M$ analysis method

those GPS stations close to plate boundaries, the implication being that these elastic displacements will change because of earthquakes which happen at plate edges.

There are situations where deformation is occurring across a broad region. For instance, motion across the Rio Grande Rift appears to be spread out over a width of hundreds of kilometers (Berglund et al. 2012). In this case, the actual deformation appears to be happening at a rate of about $1 \mathrm{nstr} /$ year, which over a $1000 \mathrm{~km}$ width results in a motion between one side and the other is small, being only $1 \mathrm{~mm} /$ year.

This does not mean that the plates so identified are "permanent". No plates are permanent but the time span for plates to remain roughly the same must vary, and it is probable that small plates last for shorter times than large plates. It also does not mean that all plates are caused by the same phenomena. Morra et al. (2013) have shown that the power spectrum of the largest 10 to 12 of the smaller plates changes over the past $60 \mathrm{Ma}$, with slopes varying from -0.2 to -0.5 , but with most results between -0.2 and -0.33 . They also found that the largest six to eight plates in the groups of large plates vary in size. This is measured as the standard deviation of the areas in the plates under consideration, and it varies between 0.6 and 4.0 over the past $200 \mathrm{Ma}$. Large numbers indicate large variations in size (heterogeneous tessellation) whereas small values indicate more uniform size distribution (homogeneous tessellation). These results show that plates can change radically over the period of a Wilson cycle. However, what we have done in this paper is to look at a single age (0 Ma), while recognizing that information of some of the very small plates described here and elsewhere will probably not be available for older ages.

The variation in area of these 159 plates is by a factor of over $380,000-$ from $104 \mathrm{Mm}^{2}$ for the Pacific plate to $273 \mathrm{~km}^{2}$ for plate 5 of Hammond et al. (2011). This huge variation calls for a logarithmic axis 
when plotting area. However, there is no reason why the plate number should not be plotted on a linear axis at this instant. This is what is shown in Fig. 1. The black line is a line through all of the 159 data. There is a distinct nick point at plate number 80 (the Danakil plate, which by chance has the median area). In this diagram, the plates are ordered in size beginning at the smallest plate. Table 1 gives the number of plates in each study that are smaller in area than the nick point.

Analysis of the data below and above the nick point reveal that the slopes of the points below and above are significantly different. In Fig. 1, the slopes of the straight lines through the data on either side of the nick point are noticeably different. This will be discussed in greater detail during a discussion of the data shown in Fig. 2. This figure shows data from below and above the nick point after having calculated a "reduced area" in the same way that seismic refraction profile data have used "reduced time" to emphasize the difference in slope between parts of a profile so that velocities may be more easily distinguished. In this case, the area represented by the $Y$ coordinate is reduced to $Y^{\prime}$ by the following equation, where $X$ is the number of the plate.

$$
\ln \left(Y^{\prime}\right)=\ln (Y)-0.0545 X
$$

The multiplication factor for $X$ is a slope which is halfway between the slopes of the lines above and below the

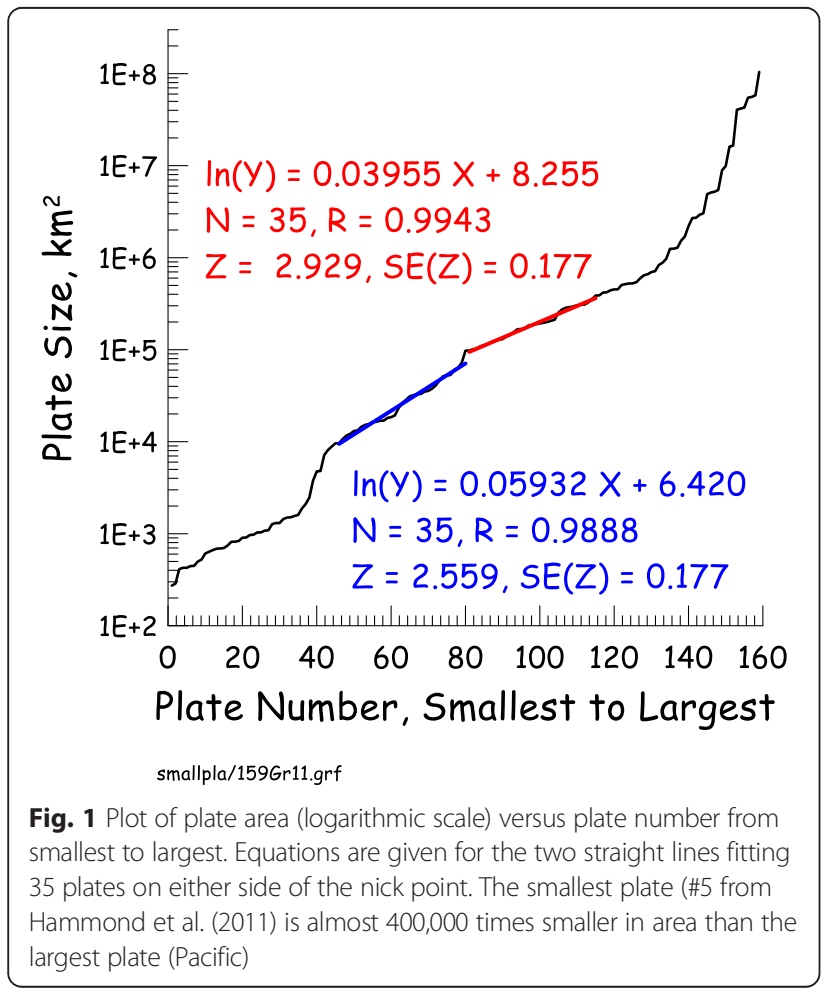

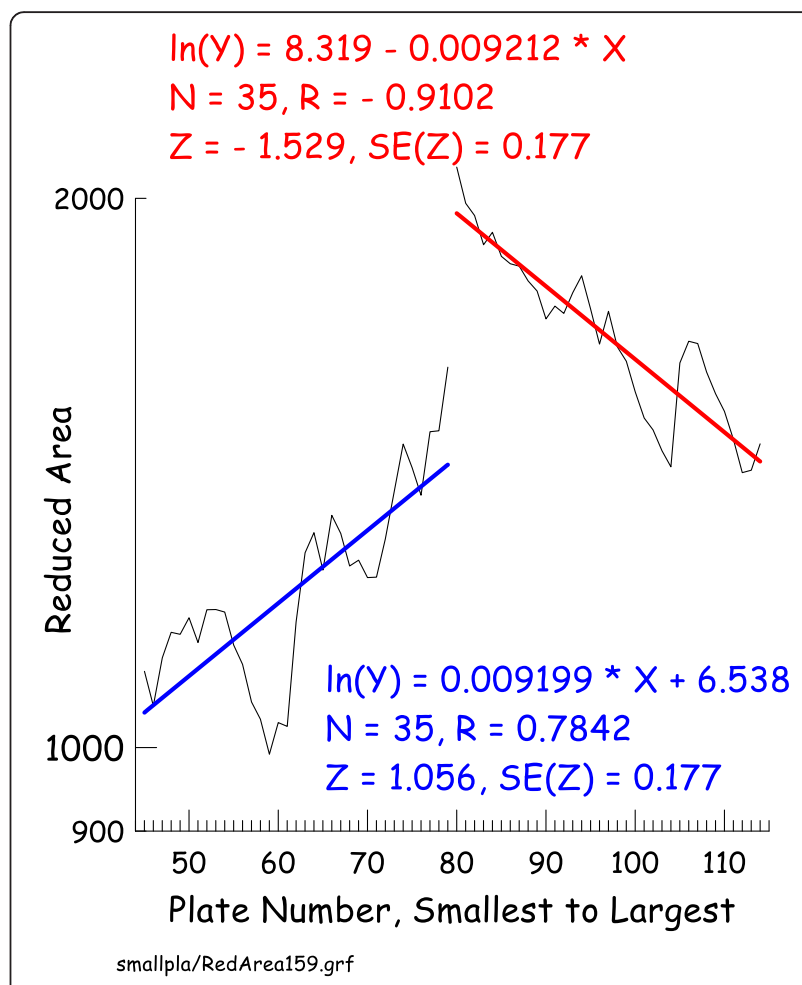

Fig. 2 Reduced area plotted against plate number (smallest to largest) for plates numbered from 46 to 115 . The reduction emphasizes the statistically significant difference in slope between the smaller data set (plates from 46 to 80 ) in contrast to the larger plates (plates from 81 to 115). This suggests that the nick point seen in Fig. 1 separates plates that may have been caused by different phenomena. The data for this figure were obtained from some of the data shown in Fig. 1 by plotting $Y^{\prime}$ in place of $Y$, where $\ln \left(Y^{\prime}\right)=$ In $(Y)-0.0481 * X$ which had a slope halfway between the slopes shown in Fig. 1. $Z$ values are the transformed correlation coefficients (Fisher 1958), and the Sigma $Z$ values are the standard errors (which depend only on the number of data pairs) of the $Z$ values

nick point in Fig. 1. This results in lines that have positive and negative slopes that are about equally different from zero. The slopes are completely different. This is illustrated by use of Fisher's (1953) reduced correlation coefficient, given in Fig. 2 along with its standard error, which only depends on the number of data pairs in the analysis.

\section{Power law behavior}

I have analyzed the distribution of plate sizes of the 159 plates to compare it with a law proposed by Koehn et al. (2008), based on a numerical model of plate rifting. They proposed that the number of plates $N$ above a certain size as measured by a linear scale, $L \mathrm{~km}$, follows a power law, as follows.

$$
N=826610 \times L^{-2.46}
$$

In order to perform the comparison, I defined a length scale for each plate by taking the radius of a circle having 
the same area as the plate $(\sqrt{ }(\operatorname{area} / \pi) \mathrm{km})$. Figure 3 shows the plot of the number of plates larger than a certain value of $L \mathrm{~km}$. Being on a $\log$-log scale, this shows the division of plates into those large plates (seven of them, in blue) falling on a steeply inclined power law curve. This type of plot is the same as the one used by Bird (2003). Bird suggested that the sizes of these largest plates were governed in some way by the finite size of the Earth. The equation governing the distribution of these seven largest plates is given by the following equation and is shown by the straight red line at the bottom right of Fig. 3.

$$
N=1.129 \times 10^{15} \times L^{-4.01}
$$

This has a much larger negative slope than do the model studies discussed by Koehn et al. (2008), and

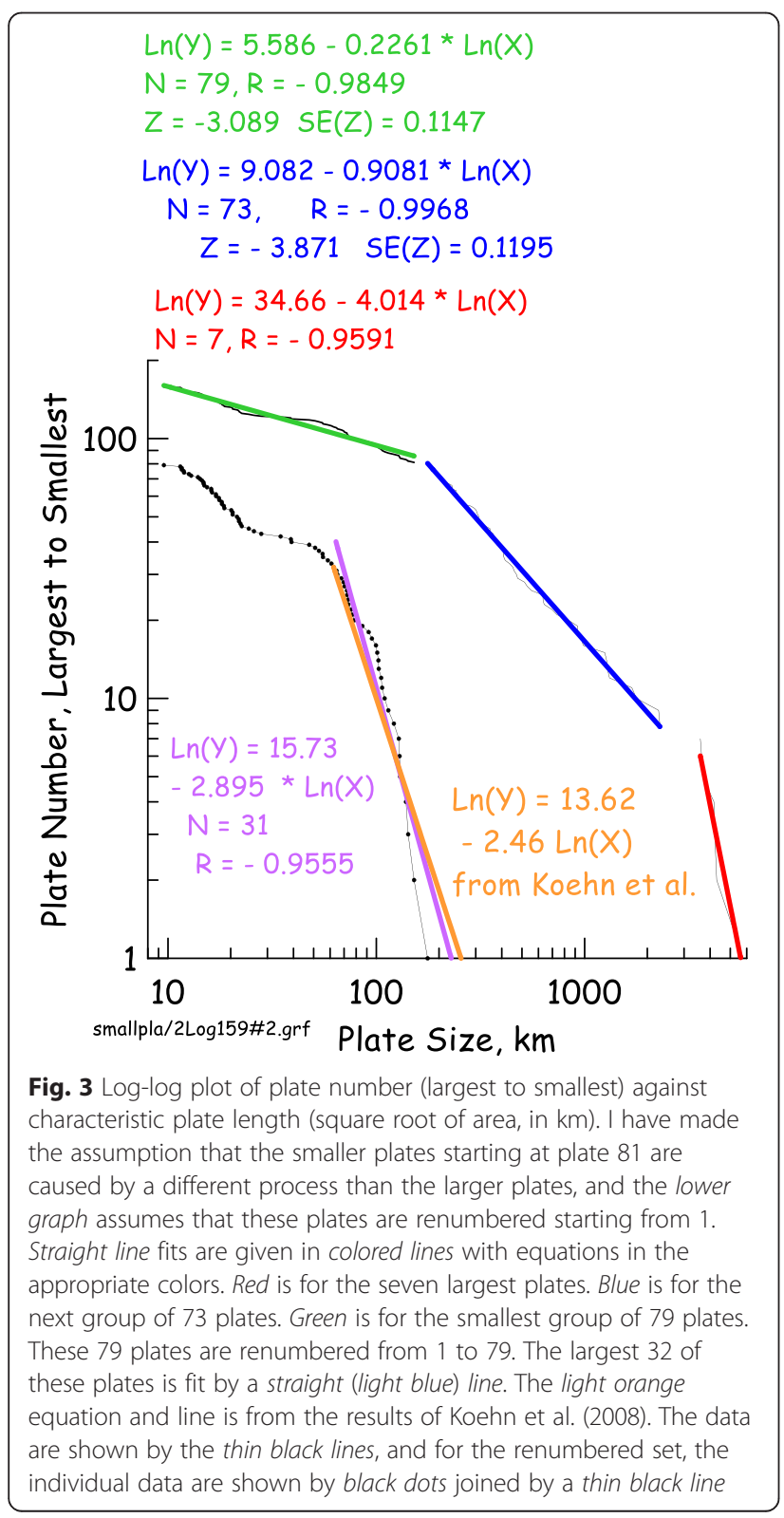

these plates are in general much larger than those created by Koehn et al. (2008) in their model studies. The characteristic length of these seven largest plates varies from 5759 to $3592 \mathrm{~km}$, i.e., much greater than Earth's mantle thickness.

The large middle section (omitting the 75 smallest plates and the seven largest plates) has a very good straight line approximation which translates into an equation as follows.

$$
N=8796 \times L^{-0.9081}
$$

This has a much smaller negative slope (the same thing as the fractal dimension) than the curve proposed by Koehn et al. (2008). It is shown as a straight blue line following the black line joining the points. If the seven largest plates had fallen on this line rather than the steeper line shown in Fig. 3, they would have been too big to fit on Earth (Bird 2003). This middle section goes from plate 8 to plate 80 . These plates have characteristic lengths between $2295 \mathrm{~km}$ (plate 8) and $176 \mathrm{~km}$ (plate 80).

If the largest plates had followed the same power law as to middle section, then plate 7 would have an area equal to $4.12 \%$ of Earth, plate 6 would have an area equal to $5.78 \%$, plate 5 would have an area of $8.65 \%$, plate 4 would have an area of $14.14 \%$, plate 3 would have an area of $26.64 \%$, and plate 2 would have an area of $65.08 \%$, and by this time, the cumulative area of the plates would be greater than Earth (by 1.45 times). The sizes of these largest plates must be controlled by the sizes of the convection currents in the asthenosphere.

The third straight line for the smallest plates has a fractal dimension of 0.2136 . This line is shown as the green line following the black line connecting the points. None of the three straight lines, representing fractal distributions, come close to the -2.5 slope of Koehn et al. (2008). Turcotte (1992) has studied fragmentation in three-dimensional situations and comes up with a fractal dimension of about 2.5, similar to the model studies of Koehn et al. (2008).

In order to investigate further the arrangement of plate sizes, I supposed that the hypothesis of Koehn et al. (2008) applies to smaller plates only. I therefore renumbered the 79 smallest plates, those smaller than the nick point in Fig. 1, starting with the largest of these plates renumbered as plate 1 . This is the black line with individual results as black dots in the lower left side of the figure. Since there is so much curvature in this line, I separated it into two segments, the one with the larger plates has 32 plates, and one having the remainder of the plates has 47 plates. The sizes of the 32 larger plates are well described by a line with an equation given below. 


$$
N=6.921 \times 10^{6} \times L^{-2.924}
$$

This is shown by the straight light blue line that follows the first 32 points. The plates analyzed for this section were chosen so that the correlation coefficient between the logarithm of plate size (abscissa) and the logarithm of plate number (ordinate), starting at new plate 1 , was maximized. In other words, if the total number of plates analyzed was either greater or less than 32 , the correlation coefficient was smaller than the number given in Fig. 3. This line is close in fractal dimension to the model results of Koehn et al. (2008) and Turcotte (1992). The Koehn et al. (2008) equation is plotted on Fig. 3 as a light orange line, and it can be seen that the agreement between this line and the best fitting line to the 32 plates shown in blue is remarkable both in intercept and in slope. The characteristic length of these 32 plates varies from 176.2 to $62.3 \mathrm{~km}$. The intercept will change as the number of plates within this size range increases, so it is somewhat of a coincidence that the intercept here is similar to that of Koehn, but the agreement in slope could indicate that the plates in this group are formed by similar forces that formed the experimental results of Koehn et al. (2008). The simulations done by Koehn et al. (2008) are specifically for a rifting situation, so that the slope of a simulation for a transform fault system or a collision system could be different. The larger plates need not be considered in this analysis because if they are formed by different causes, then, it is legitimate to consider only those plates that may be formed by the specific forces, whatever they are, producing the very small plates. The change in slope illustrated by the bottom curve in Fig. 3 between the smallest 47 plates and the larger set of 32 plates may also indicate missing plates in the very small size category. Discovery of additional plates with areas between plate 1 and plate 32 on the lower graph in Fig. 3 might change the slope of this line. The conclusion is that the size distribution of this group of plates is very close to the modeling and observational results of Turcotte (1992) and Koehn et al. (2008). Analysis of plate size if the blocks from Bird and Rosenstock are substituted by the blocks from Meade and Hager gives similar results although with a somewhat less clear picture than is given in Fig. 3. There is still a kink in the slope of the upper curve between the 79 smallest plates and the larger plates. And replotting the renumbered smaller plates gives a similar slope for the larger group of this smallest set of blocks. It seems likely that this mode of plate formation may be found when the characteristic length of the plates becomes close to the thickness of the lithosphere.

So after the addition of the plates described above, we end up with four sets of plate sizes. The 47 smallest plates have a distinctly different slope from the next set of 32 plates, as illustrated in the lower curve in Fig. 3. Both of these lowest groups may be biased because of inadequate analysis of very small plates from many other plate boundaries. Also, it has to be remembered that many of the studies of small plates are not complete because the parts of the boundaries of some of the plates are missing, making it impossible to measure their areas and so rendering them not amenable to be added to the plate list. The bulk of the remaining plates fall into the group of 73 plates with a very well-fitting straight line on the log-log plot in Fig. 3. The largest group of seven plates (already identified by Bird 2003) has a steeply sloping best fit line.

\section{Discussion}

Sornette and Pisarenko (2003) studied the relationship between area and plate number using an earlier model of Bird which contained 42 plates and which was an early version of Bird's (2003) paper. They came to the conclusion that the separation between the seven largest plates (South America to Pacific) with a steeply descending line showing cumulative area as a function of plate number starting with the largest plate and the smaller set of plates with a smaller negative slope could not be conclusively proved. Their model was derived from a Pareto distribution. Morra et al. (2013) have undertaken a detailed study of plate size as a function of time before present, back to $200 \mathrm{Ma}$. They point out that the number of plates identified becomes smaller the older the plate reconstruction. They used 31 plates for the present and only 10 for the time $200 \mathrm{Ma}$ ago. They plotted the $\log$ of cumulative plate area in square kilometers (in contrast to the similar plot in Bird (2003) and in this paper where the $\log$ of cumulative linear plate size is plotted against log of plate number (Fig. 3). Morra et al. (2013) showed that the first slope break happened regularly at about plate 7 or 8 , which is consistent with the results in Fig. 3 where the break has been made between plate 7 and plate 8 . They showed that this division between the very large plates and the next set of plates is almost certainly permanent for the time period that they considered $(200 \mathrm{Ma})$ in contrast to the supposition of Sornette and Pisarenko (2003). Morra et al. (2013) analyzed in detail the slope of the curve showing the log of plate number (from large to small) and log of plate area, but they left out the plates smaller than plate number 21 so as to limit the variation of plate area as a function of epoch. Depending on exactly which set of data is used, their slope for log (plate number) versus log (cumulative plate area) was similar to the slope of the first seven plates of this data set. Their standard deviation of the plate sizes for the first set of largest plates was $2 \times$ $10^{7} \mathrm{~km}^{2}$ for the largest set of plates (present day 
calculation), compared with $2.21 \times 10^{7} \mathrm{~km}^{2}(2.50 \times$ $10^{7} \mathrm{~km}^{2}$ ) for the seven (eight) largest plates in this compilation. For their set of ten smaller plates, the slope varied between about -0.2 and -0.4 . The analysis here using many more plates shows that the slope of the curve for the 73 plates is -0.454 . Their analysis argued that there was a strong likelihood that the plates could in fact be divided into the seven larger plates and the smaller ones based on data similar to that shown in Fig. 3.

The largest seven plate movements are closely coupled to mantle convection (Quéré and Forte 2006). It seems likely that the movement of the next set of 73 plates is controlled partly by mantle convection and partly by edge effects caused by the movement of other plates in close proximity.

In addition to the 52 plates in Bird's (2003) catalogue, another 107 plates have been identified. The areas of these plates was somewhat concentrated at the lower end of the area scale, but there were significant numbers of medium-sized plates starting with the Capricorn plate which is about $1 \%$ of Earth's area and is the 14th largest plate. One of these plates has no rotation vector as yet. The plate size distribution illustrated by Bird (2003) is greatly changed by the addition of these other plates which were found mainly using the new technique offered by the relatively inexpensive (in contrast to other space-based systems such as VLBI and SLR) GPS instruments to measure accurately small relative motions. Overall, the plate size distribution as illustrated in Figs. 1, 2 , and 3 shows that there is a significant kink in the distribution between the 80th and the 81st plates, counting from large to small. If these plates (81st to 159th in size) are thought to be caused by a different phenomenon than the larger plates, then, it is reasonable when plotting the plate sizes starting with the largest as plate 1 to restart the numbering below this kink. The size distribution of the 32 largest set of plates in this small size range has a slope on the log-log plot of -2.924 (Fig. 3). This is almost the same as the results from model studies done by Koehn et al. (2008) and in Turcotte's (1992) analysis, who found slopes averaging around -2.5 in their studies.

Additional file 1: Table S10 lists the 32 plates that are represented in Fig. 3 by the bottom part of the pink curve and its best fitting black line. It shows that most of the plates lie in continental areas. There could be several reasons for this. (1) There is in fact a greater likelihood that very small plates fall in continental areas. (2) It is more difficult to do the detailed analyses necessary to find small plates in the ocean basins. (3) You cannot do GPS measurements attached to oceanic basin areas, a method that has produced many small plates on land.

Since few areas have been studied in the detail done by Bird and Rosenstock (1984) and other papers mentioned here, there are very likely to be many more plates waiting to be discovered. However, if very small plates are created preferentially at transform faults, then, this discovery becomes more difficult because most transform faults are in oceanic areas and so are less capable of being explored in the detail necessary to find these small plates. In their paper, Bird and Rosenstock (1984) emphasize that much detailed field work was necessary to map the faults separating the plates in their model. Alternatively, there has to be a major investment in GPS stations (Meade and Hager 2005) to accomplish this task. Maybe very detailed swath mapping and deep towed magnetic field analysis of relevant oceanic areas would be capable of detecting such faults in the deep ocean (Harrison 1987; Tivey et al. 2006; Zhu et al. 2010). On the other hand, it may be that oceanic crust and mantle is much less capable of forming microplates, in which case, attention will have to be given to those places where there are continental transform faults. One such fault is the Motagua fault, the boundary between the North America and the Caribbean plates that runs through Guatemala. There is a portion of the boundary between the South America plate and the Scotia plate that runs through the southern end of South America. There is a transform fault running from the spreading center in the Red Sea up to the Gulf of Aqaba through the Dead Sea, Jordan valley, and Sea of Galilee, separating the Sinai plate (Additional file 1: Table S2) from the Arabian plate. There are some complex transform faults in SE Asia that could yield information, as well as the Alpine fault in the south island of New Zealand. These transform fault locations were taken from the PLATES Project digital data compilation of the University of Texas).

One place where more plates might be found is along the northern Caribbean boundary, which is a mainly strike slip (transform) boundary, where the Gonâve and Puerto Rico plates have been discovered (Additional file 1: Table S2). Each of the Gonâve and Puerto Rico plates is larger in area than the sum of the plates listed in Additional file 1: Table S3, but unfortunately, these two plates are predominantly oceanic plates.

Stock and Lee (1994) have suggested that oceanic plates as they approach ocean-continent subduction zones may sometimes break off microplates. They use as an example the subdivision of the Farallon plate, which is now represented by the Nazca, Cocos, Rivera, Gorda, Juan de Fuca, and Explorer plates. The Farallon plate is pretty big compared with most of the 159 plates talked about in this paper.

Anderson (2002) has suggested that the number of plates to be expected could be done by consideration of the ability of plates or bubbles to cover a sphere which he thinks is about 12. Bird (2003) has suggested that the 
seven largest plates have a different arrangement of size as a function of plate number, as can be seen in Fig. 3 (log-log plot) but not as easily in Fig. 1 (log-linear plot). But there does not seem to be any significant break at around the 12th largest plate in any of these figures. It may be that this idea of Anderson is manifested in the significant break at the seventh largest plate as these seven largest plates cover about $80 \%$ of Earth's area.

The use of space-based geodetic techniques offers up the opportunity of obtaining results not available by using the normal geological and seismological techniques, partly because of the different time constant of the measurements and partly because of different plate coverage. Strangely, although the MORVEL model of DeMets et al. (2010) uses space-based data to determine the velocities of four plates (Amur, Philippine Sea, Sundaland, and Yangtze) and partly to determine the velocities of two more plates (Caribbean and Scotia), complete merging of these two data types has not been done. If this were to happen, then, it should be possible to determine not only present-day rotation vectors but also vector rates-of-change, as has been done already for specific plates (Norabuena et al. 1999). It would also help in resolving the discrepancies between the two different interpretations of the southern California shear zone (Bird and Rosenstock 1984; Meade and Hager 2001).

\section{Conclusions}

Sizes of plates currently known or proposed vary by a factor of more than $3.8 \cdot 10^{5}$ in area. They can be divided up into four groups by examination of how the size changes as a function of plate number if the plates are arranged in order of size. The seven largest plates show a large decrease in plate size from one plate to the next and comprise $78.02 \%$ of Earth's area. The next set of 73 plates added to the first number is $99.7886 \%$ of Earth's area, leaving $.2114 \%$ for the other plates. The third group of 32 plates increases the total to $99.9796 \%$ leaving only $.0204 \%$ of Earth's area for the smallest group of 47 plates. When plotted on a $\log / \log$ plot using size (abscissa) against order (large to small, ordinate), each of the three larger groups has a best fitting straight line with a distinctive slope which accurately follows the individual plate areas, while the group of smallest plates does not follow any such behavior. Each break in slope may represent a different underlying cause. If there were no change in the slope between the seven largest plates and the rest, then, we would be limited to only four more plates before the whole Earth would be covered, but they would have to have very odd shapes. It should be noted that none of the 31 plates in Hammond et al. (2011) is large enough to be included in the third set of plates, being too small to be included in this list. At present, they do not greatly impact the agreement between this paper and the results of Koehn et al. (2008) and Turcotte (1992).

One break in slope (equivalent to the break between the group of second-largest plates and third-largest plates) was identified by Bird as suggesting that more plates were present than the 52 that he had in his catalogue. Although we have found 107 more plates in the literature, the change in slope is still there. Of these 107 plates, 79 are smaller than the nick point. This may represent the change from plates that are more permanent from the ones produced during breakup aligned with the major plate boundaries along the lines suggested by Koehn et al. (2008). The final change in slope may represent the result of missing plates due to a lack of detailed study. This could be solved either geologically or by dense space-based geodetic networks. In oceanic areas, it may be much more difficult but attempts could be made by near-bottom observation of topography (Spiess et al. 1969), by swath mapping and by near-bottom observation of the magnetic field (Luyendyk et al. 1968).

There does not seem to be strong evidence that smaller plates are formed preferentially at different types of plate boundaries. But there is still a possibility that there could be such an effect, which could be more easily determined if we had studies such as those done in the Southern California Shear Zone performed elsewhere.

Finally, several questions need to be answered by a study of small plates.

(1) Will small plates be mostly associated with continental transform faults, or with continental AND oceanic transform faults, or some other type of plate boundary, or will they be equally likely to be found on all types of plate boundary?

(2)Will other studies reveal a power law relationship between plate size and number of plates larger than this size, and what is the power law slope?

(3) What are the forces that produce small plates, and do they vary according to the original tectonic setting?

(4) How do the forces that move plates change as a function of plate size?

(5) What is the smallest size for which the concept of a plate remains useful?

\section{Additional file}

Additional file 1: Tables S1-S10. Table S1. Matrix of plates and models. Table S2. List of 23 plates added to the Bird (2003) catalogue. Table S3. Comparison of Southern California Shear Zone from Bird and Rosenstock (1984) and McCaffrey (2005). Table S4. Thirty-one plates from Hammond et al. (2011). Table S5. Plates from Reilinger et al. (2006) 
Table S6. Eleven small plates from Thatcher (2007). Table S7. Five plates from Meade and Hager (2001). Table S8. Five plates from Wallace et al. (2004b). Table S9. Seventeen plates from Meade and Hager (2005). Table S10. List of 32 smallish plates and their geological settings. (DOCX $51 \mathrm{~kb}$ )

\section{Competing interests}

The author declares that he has no competing interests.

\section{Acknowledgements}

I have benefitted from discussions with Tim Dixon, Peter La Femina, Kim Outerbridge (Psencik), Gina Schmalzle, and Shimon Wdowinski, and also to Patrick. M. S. Blackett, who got me interested in paleomagnetism and continental drift which led me to plate tectonics.

\section{Received: 27 August 2015 Accepted: 5 February 2016 Published online: 02 March 2016}

\section{References}

Abdrakhmatov, Ye K, Aldazhanov SA, Hager BH, Hamburger MW, Herring TA, Kalabaev KB, Makarov VI, Molnar P, Panasyuk SV, Prilepin MT, Reilinger RE, Sadybakasov IS, Souter BJ, Yu A, Trapeznikov V, Tsurkov VY, Zubovich AV (1996) Nature 384:450-453

Anderson DL (2002) How many plates? Geology 30:411-414

Argus DF, Gordon RG, Heflin MB, Ma C, Eanes RJ, Willis P, Peltier WR, Owen S (2010) The angular velocities of the plates and the velocity of Earth's centre from space geodesy. Geoophys J Int 180:913-960. doi:10.1111/j.1365-246X. 2009.04463.x

Berglund HT, Sheehan AF, Murray MH, Roy M, Lowry AR, Nerem RS, Blume F (2012) Distributed deformation across the Rio Grande Rift, Great Plains, and Colorado Plateau. Geology 40:23-26. doi:10.11.30/G32418.1

Bevis M, Cambareri G (1987) Computing the area of a spherical polygon of arbitrary shape. Math Geol 19:335-346

Bird P (2003) An updated digital model of plate boundaries. Geochem Geophys Geosyst 52. 1027. doi:10.1029/2001GC000252

Bird P, Rosenstock RW (1984) Kinematics of present crust and mantle flow in southern California. Geol Soc Am Bull 95(946-957):1984

Cavalié O, Jónsson S (2014) Block-like plate movements in eastern Anatolia observed by InSar. Geophys Res Lett 41:26-31. doi:10.1002/2013GL058170

Chase CG (1972) The N plate problem of plate tectonics. Geoophys J Roy Astron Soc 29:117-122

Chase CG (1978) Plate kinematics: the Americas, East Africa, and the rest of the world, Earth Planet. Sci Lett 37:355-368

DeMets C, Gordon RG, Argus DF, Stein S (1990) Current plate motions. Geophys J Int 101:425-478

DeMets C, Gordon RG, Argus DF, Stein S (1994) Effect of recent revisions to the geomagnetic reversal timescale. Geophys Res Lett 21:2191-2194

DeMets C, Gordon RG, Argus DF (2010) Geologically current plate motions. Geophys J Int 181:1-80

Fisher RA (1958) Statistical methods for research workers, Thirteenthth edn. Oliver and Boyd, Edinburgh, p 356

Flesch LM, Haines AJ, Holt WD (2001) Dynamics of the India-Eurasia collision zone. J Geophys Res 106:16435-16460

Forsyth D, Uyeda S (1975) On the relative importance of the driving forces of plate motion. Geophys J Roy Astron Soc 43:163-200

Hall R, Spakman W (2003) Mantle structure and tectonic evolution of the region north and east of Australia, in "Evolution and Dynamics of the Australian Plate". In: Hills RR, Muller RD (eds) The Geological Society of America Special Paper 372., pp 361-381

Hammond WC, Thatcher W (2007) Crustal deformation across the Sierra Nevada, northern Walker Lane, Basin and Range transition, western United States measured with GPS, 2000-2004. J Geophys Res 112:26. doi:10.1029/ 2006JB004625

Hammond WC, Blewitt G, Kreemer C (2011) Block modeling of crustal deformation of the northern Walker Lane and Basin and Range from GPS velocities. J Geophys Res 116:28. doi:10.1029/2010JB007817

Harrison CGA (1987) Marine magnetic anomalies-the origin of the stripes. Ann Rev Earth Planet Sci 15:505-543

Harrison CGA, Douglas N (1990) Satellite laser ranging constraints on plate motion. Tectonics 9:935-952
Jennings CW (1994) Fault activity map of California and adjacent areas with location and ages of recent volcanic eruptions, Calif. Geol. Data Map Ser., Map 6, Calif. Dept. of Conserv., Div. of Mines and Geol, Sacramento

Johnson CA, Harrison CGA (1990) Neotectonics in central Mexico. Phys Earth Planet Int 64:187-210

Klein EM, Smith DK, Williams CM, Schouten H (2005) Counter-rotating microplates at the Galapagos triple junction. Nature 433:855-858

Koehn D, Aanyu K, Haines S, Sachau T (2008) Rift nucleation, rift propagation and the creation of basement micro-plates within active rifts. Tectonophysics 458 105-116. doi:10.1016/j.tecto.2007.10.003

Kogan MG, Steblov GM (2008) Current global plate kinematics from GPS (1995-2007) with the plate-consistent reference frame. J Geophys Res 113:B04416. doi:10.1029/2007JB005353

Kreemer C, Holt WE, Haines AJ (2003) An integrated global model of present-day plate motions and plate boundary deformation. Geophys J Int 154:8-34

Kusky TM, Toraman E, Raharimahefa T, Rasoazanamparany C (2010) Active tectonics of the Alaotra-Ankay Graben System, Madagascar: possible extension of Somalian-African diffusive plate boundary? Gondwana Research 18:274-294

Larson KM, Freymueller JT (1997) Global plate velocities from the Global Positioning System. J Geophys Res 102:9961-9981

Le Pichon X (1968) Sea-floor spreading and continental drift. J Geophys Res 73: $3661-3697$

Le Pichon X (1970) Correction to Paper by Xavier Le Pichon 'Sea-floor spreading and continental drift'. J Geophys Res 75:2793

Lithgow-Bertelloni C, Richards MA (1998) The dynamics of Cenozoic and Mesozoic plate motions. Rev Geophys 36:27-78

Luyendyk BP, Mudie JD, Harrison CGA (1968) Lineations of magnetic anomalies in the Northeast Pacific observed near the ocean floor. J Geophys Res 73:5951-5957

McCaffrey R (2005) Block kinematics of the Pacific-North America plate boundary in the southwestern United States from inversion of GPS, seismological, and geologic data. J Geophys Res 110:B07401. doi:10.1029/2004JB003307

McKenzie DP (1970) Plate tectonics of the Mediterranean region. Nature 226: 239-243

McKenzie DP (1972) Active tectonics of the Mediterranean region. Geophys J Roy Astron Soc 30:109-185

McKenzie DP, Davies D, Molnar P (1970) Plate tectonics of the Red Sea and East Africa. Nature 226:243-248

Meade BJ, Hager BH (2001) The current distribution of deformation in the western Tian Shan from block models constrained by geodetic data. Geol Geof 42:1622-1633

Meade BJ, Hager BH (2005) Block models of crustal motion in southern California constrained by GPS measurements. J Geophys Res 110:B03403. doi:10.1029/ 2004JB003209, 19 pp

Meade BJ, Hager BH, McKlusky SC, Reilinger RE, Ergentav S, Lenk O, Barba A, Ozener H (2002) Estimates of seismic potential in the Marmara Sea region from block models of secular deformation constrained by Global Positioning System measurements. Bull Seismol Soc Am 92:208-215

Madiera J, Ribeiro A (1990) Geodynamic models for the Azores triple junction: a contribution from tectonics. Tectonophysics 184:405-415

Minster JB, Jordan TH (1978) Present-day plate motions. J Geophys Res 83:5331-5354

Minster JB, Jordan TH, Molnar P, Haines E (1974) Numerical modeling of instantaneous plate tectonics. Geophys J Roy Astron Soc 36:541-576

Morgan WJ (1968) Rises, trenches, great faults, and crustal blocks. J Geophys Res 73:1959-1968

Morgan WJ (1971) Plate motions and deep mantle convection. In: Shagam R, Hargraves RB, Morgan WJ, Van Houten FB, Burk CA, Holland HD, Hollister LC (eds) Studies in Earth and space sciences Hess, Volume Geol. Soc. Am. Mem. 132, Boulder Colorado, USA

Morra G, Seton M, Quevado L, Müller RD (2013) Organization of the tectonic plates in the last 200 Myr. Earth Planet Sci Lett 373:93-101

Norabuena EO, Dixon TH, Stein S, Harrison CGA (1999) Decelerating Nazca-South America and Nazca-Pacific plate motions. Geophys Res Lett 26:3405-3408

Quéré S, Forte AM (2006) Influence of past and present-day plate motions on spherical models of mantle convection: implications for mantle plumes and hotspots. Geophys J Int 165:1041-1057. doi:10.1111/j.1365-246X.2006. 02990.x 
Reilinger R, McClusky S, Vernant P, Lawrence S, Ergintav S, Cakmak R, Ozener H, Kadirov F, Guliev I, Stepanyan R, Nadariya M, Hahubia G, Mahmoud S, Sakr K, ArRajehi A, Paradissis D, Al-Aydrus A, Prilepin M, Guseva T, Evren E, Dmitrosta A, Filikov SV, Gomez F, Al-Ghazzi R, Karam G (2006) GPS constraints on continental deformation in the Africa-Arabia-Eurasia continental collision zone and implications for the dynamics of plate interactions. J Geophys Res 111:B05411. doi:10.1029/2005JB004051

Robaudo S, Harrison CGA (1993) Plate tectonics from SLR and VLBI global data, in "Contributions of space geodesy to geodynamics: crustal dynamics". In: Smith DE, Turcotte DL (eds) AGU, Geodynamics Series Volume 23., pp 51-71

Sella GF, Dixon TH, Mao A (2002) REVEL: a model for recent plate velocities from space geodesy. J Geophys Res 107(B4). 10.1029/2000JB00033

Shen Z-K, Lu J, Wang M, Bürgmann R (2005) Contenporary crustal deformation around the southeastern borderland of the Tibetan Plateau. J Geophys R 110. doi:10.1029/2004JB003421

Sornette D, Pisarenko V (2003) Fractal plate tectonics. Geophys Res Lett 30. doi:10.1029/2002GL015043

Spiess FN, Luyendyk BP, Larson RL, Normark WR, Mudie JD (1969) Detailed geophysical studies on the Northern Hawaiian arch using a deeply towed instrument package. Mar Geol 7:501-527

Stock JM, Lee J (1994) Do microplates in subduction zones leave a geological record. Tectonics 13:1472-1487

Thatcher W (1995) Microplate versus continuum descriptions of active tectonic deformation. J Geophys Res 100:3885-3894

Thatcher W (2007) Microplate model for the present-day deformation of Tibet. J Geophys Res 112. doi:10.1029/2005JB004244

Thatcher W (2009) How the continents deform: the evidence from tectonic geodesy. Annual Rev Earth Planet Sci 37:237-262. doi:10.1146/annualrev. earth.031208.100035

Tivey MA, Sager WW, Lee S-M, Tominaga M (2006) Origin of the Pacific Jurassic quiet zone. Geology 34:789-792. doi:10.1130/G22894.1

Turcotte DL (1992) Fractals and chaos in geology and geophysics. Cambridge University Press, Cambridge, UK, 221 pp

Wallace LM, Stevens C, Silver E, McCaffrey R, Loratung W, Hasiata S, Stanaway R, Curley R, Rosa R, Taugaloidi J (2004a) GPS and seismological constraints on active tectonics and arc-continent collision in Papua New Guinea: implications for mechanics of microplate rotations in a plate boundary zone. J Geophys Res 109. doi:10.1029/2003JB002481

Wallace LM, Beavan J, McCaffrey R, Darby D (2004b) Subduction zone coupling and tectonic block rotations in the North Island, New Zealand. J Geophys Res 109. doi:10.1029/2004JB003241

Zhu J, Lin J, Chen YJ, Tao C, German CR, Yoerger DR, Tivey MA (2010) A reduced crustal magnetization zone near the first observed active hydrothermal vent field on the Southwest Indian Ridge. Geophys Res Lett 37. doi:10.1029/ 2010GL043542

\section{Submit your manuscript to a SpringerOpen ${ }^{\mathcal{O}}$ journal and benefit from:}

- Convenient online submission

Rigorous peer review

- Immediate publication on acceptance

- Open access: articles freely available online

High visibility within the field

- Retaining the copyright to your article

Submit your next manuscript at $\gg$ springeropen.com 